\title{
Review
}

\section{Applicability of Spray Drying Technique to Prepare Nano-Micro Carriers: A Review}

\author{
Archana Mishra* ${ }^{\circledR}$, Jitendra Kumar, Kuber Chandra Bhainsa \\ Nuclear Agriculture and Biotechnology Division, Bhabha Atomic Research Centre, Trombay, Mumbai, India \\ E-mail: archanam@barc.gov.in
}

Received: 8 October 2021; Revised: 7 December 2021; Accepted: 7 December 2021

\begin{abstract}
Nano-micro carriers loaded with drugs and active biomolecules have gained a lot of attention in the field of health care, agriculture, and the food industry. Various methods have been explored to synthesize nano-micro carriers. However, there is still a constant search to develop a method for the preparation of a large quantity of nano-micro carriers with high loading efficiency. In this regard, spray drying could be a potential technique because of its inherent features like ease to operate, cost-effectiveness, environment-friendly, single step, and scalable. In this review, the focus is on the applicability of spray drying technique to prepare nano-micro carriers which are loaded with drugs, microorganisms, and other active molecules. Subsequently, the application and usefulness of spray-dried products in different research areas like the food industry, remediation of heavy metals and bioprocessing, and drug delivery have been presented. Furthermore, advantages, limitations, and recent developments in the area of spray drying have been discussed. This review presents a glimpse of spray drying techniques to synthesize nano-micro carriers with a wide range of applications.
\end{abstract}

Keywords: spray drying, nano-micro carriers/formulations, food industry, silica nanoparticles, remediation, enzymes, bioprocessing, drug delivery

\section{Introduction}

In recent years, a lot of work has been carried out to develop carriers for various applications in the field of health care, agriculture, food, and biotechnology. A wide range of nanocarriers, hybrid carriers, and microcarriers were synthesized. In this regard, various techniques like emulsion polymerization, freeze-drying, intercalative polymerization, sol-gel method, hybrid latex polymerization, etc., have been deployed for the production of carriers [1-4]. However, some of these methods are multi-step physical/chemical processes wherein various chemicals are used leading to an increase in cost and generation of waste. Among these techniques, the sol-gel technique is one of the popular and widely used techniques. The sol-gel technique is a versatile technology for the synthesis of carriers and the immobilization of various biological molecules $[5,6]$. Using the sol-gel technique, various inorganic, composites and hybrid carriers loaded with drugs, growth factors, antibodies/antigens, nucleic acids, proteins, enzymes, prokaryotic and eukaryotic cells have been prepared [7-9]. For the preparation of silica-based carriers, sol-gel is one of the preferred methods [10]. However, the generation of alcohol during the sol-gel process limits the use of silica-based carriers for in vivo

Copyright (C2021 Archana Mishra, et al.

DOI: https://doi.org/10.37256/nat.3120221198

This is an open-access article distributed under a CC BY license

(Creative Commons Attribution 4.0 International License)

https://creativecommons.org/licenses/by/4.0/ 
applications and immobilization of sensitive biomolecule [10-12].

With the advent of nanotechnology, nanoparticles have emerged as the material of choice to develop carriers with slow-release kinetics and high loading efficiency [1,13]. Various nanoparticles of inorganic, organic, and biological origin have been applied as carriers [14]. The nanoparticles were also applied as the carrier to develop nanoparticlesbased hybrid carriers for various applications. Nanoparticles-based carriers and hybrid carriers offer a number of advantages like high surface area, biocompatibility, encounters the issue of the low solubility of drugs, and hence improving the bioavailability of poorly soluble drugs [15-17]. A number of nanoparticles-based carriers/formulations like nanocomplexes, polymeric micelles, and nanoparticles, liposomes, nanoemulsions, and nanocrystals have been synthesized and applied for drug delivery applications [18].

Among various nanoparticles, silica nanoparticles have shown their superiority due to their characteristic features like biocompatibility, wide availability, ease of functionalization, high chemical, and mechanical stability, and high surface area [19-21]. Ponamoreva et al. [22] have synthesized a stable functional biohybrid material by integrating yeast cells with silica for biosensor application. It is well documented that silica, which is a major component of the cell wall of diatoms, acts as a protective covering [23]. Also, silica has been applied as immobilizing support for living cells [24, 25]. Silica Nanoparticles (NPs) have imparted momentum in the field of drug delivery and bioprocessing and it has been widely applied to prepare various carriers/formulations. There are two widely used methods to prepare silica-based hybrid carriers i.e., template-assisted assembly and self-assembly. In 2017, silica NPs were assembled on the surface of Sphingomonas sp. cells, immobilized on the microplate, and applied as bio components for the development of a sensitive and stable biosensor for detection of methyl parathion [10]. Also, we have assembled silica NPs on the surface of Ocimum basilicum seeds to develop a bio-hybrid of silica NPs-seeds and used it as an immobilizing matrix for the immobilization of industrially applicable invertase enzyme [14]. Due to association with silica NPs, the surface area of the developed matrix was increased and the matrix emerged as an efficient immobilizing matrix with improved catalytic performance.

Following the evaporation-induced self-assembly process of spray drying, our lab has explored this technique extensively for immobilization of various biomolecules (Streptococcus lactis cells, Saccharomyces cerevisiae cells) [26-29] and doxorubicin as a chemotherapeutic drug using silica nanoparticles as support material. Further, developed biohybrids were applied for their respective applications and the detail of the work will be discussed in the coming sections. Due to its varying range of applications, spray drying has emerged as a suitable, simple, single-step, and costeffective technique to synthesize formulations in large quantity with reproducibility. The next section of the review will focus on various aspects of spray drying such as working principle, types of microstructures synthesized using spray drying and their applications, advantages associated with spray drying, and recent developments in the field of spray drying.

\section{Spray drying}

Spray drying is a widely applied technique for the preparation of powdered products using liquid/aqueous feed samples by atomization in a hot drying air stream in a drying chamber. In recent years, spray drying has emerged as one of the remarkable techniques which holds a prominent place in the field of pharmaceuticals and the food industry [30]. It has been successfully used for the preparation of various microstructures like microspheres and microcapsules for drug delivery applications. Also, it has shown its applicability as an immobilizing technique for the immobilization of biologically active molecules and cells.

It is a continuous process that converts, a liquid/aqueous feed into a powder, in a single-step process with precision in particle size, morphology, and stability. The feed-in spray drying could be suspensions, aqueous solutions, emulsions, slurries, pastes, etc. [31, 32]. The process is highly reproducible and scalable. Spray drying works on the principle of Evaporation-Induced Self-Assembly (EISA). Figure 1, shows the schematic presentation of the spray drying instrument and its working process. The fundamental steps of the spray drying process are listed below:

(a) Atomization of the feed: First, the liquid feed is passed into the drying chamber by a peristaltic pump through the nozzle (atomizer). The nozzle can be of various types like pressure nozzle, rotary nozzle, two-fluid nozzle and the factors responsible for the atomization are pressure, centrifugal force, and kinetic energy, respectively [33]. The nozzle 
converts the feed into very fine (micron/sub-micron size) droplets.

(b) Droplet-to-particle conversion: The small droplets generated through the nozzle in the drying chamber undergo fast solvent evaporation $[34,35]$ and leads to the formation of dry particles. The small droplets being very small in size offer high surface area and undergo very fast drying as they come in contact with hot air/gas.

(c) Separation and particle collection: Dried particles get separated from the drying gas by means of a cyclone which collects them in a collector [36]. Spray-dried products have shown higher chemical and physical stability in comparison to liquid formulations. The dried products have been exploited in various applications, for example, they can be filled in the capsules or tablets of the suitable doses that can be prepared [37, 38].

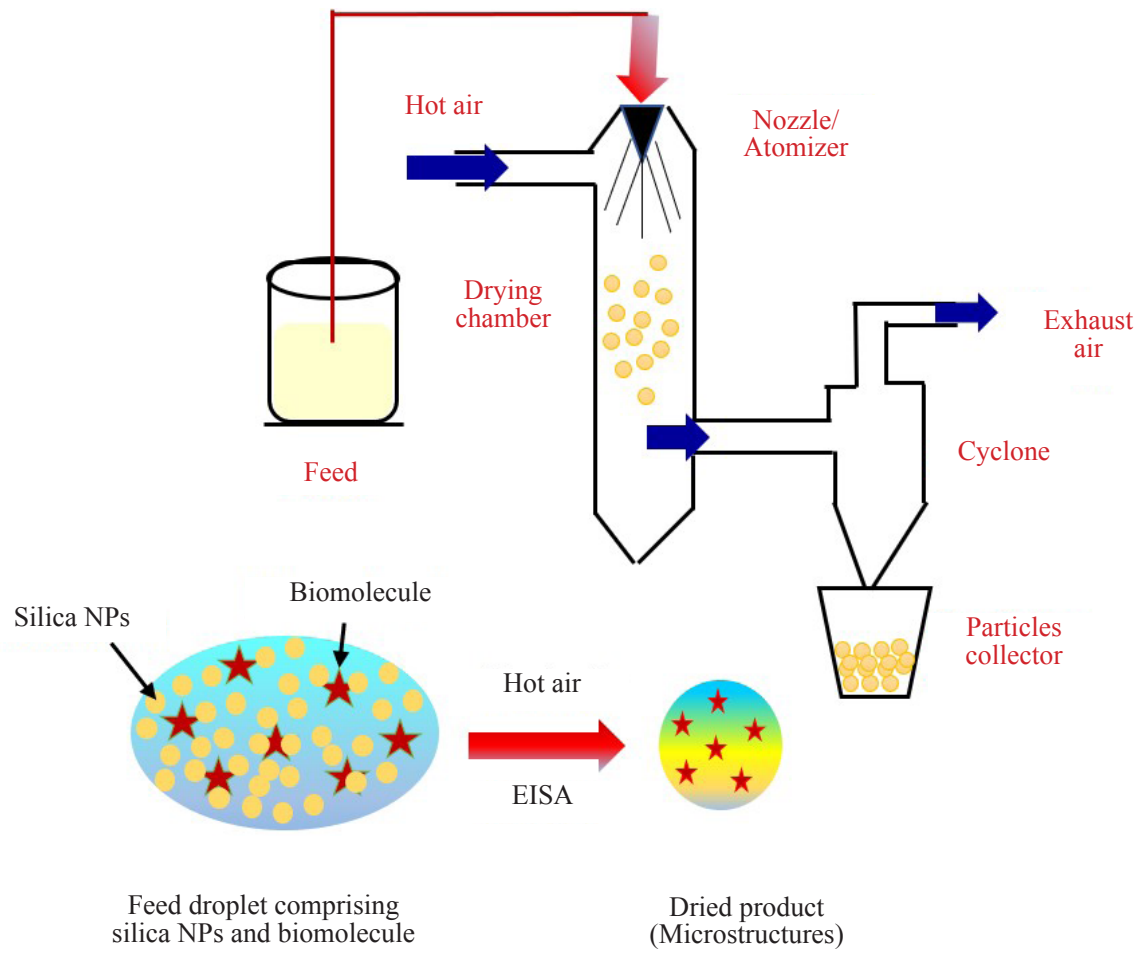

Figure 1. Schematic presentation of spray dryer instrument, its working process, and process of Evaporation Induced Self-Assembly (EISA)

The final properties and morphology of the dried products are determined by a variety of factors like the feed characteristics, spray dryer design, drying temperature, and processing parameters. By tuning spray drying parameters, one can synthesize spray-dried products with desirable characteristics [27]. As shown in Figure 2, the feed comprising silica NPs with S. lactis cells leads to the formation of doughnut-shaped structures (Figure 2(a) and (b)). However, when the surface polarity of $S$. lactis cells was reversed, then positively charged cells along with silica NPs as feed led to the formation of sphere-shaped structures (Figure 2(c) and (d)) [27]. This study clearly shows the influence of the surface charge of feed components on the morphology of spray-dried products. Alamilla-Beltranet et al. [39] have explained the morphological transformations of the particles during spray drying.

The scalability property of the spray drying technique favours preparing dried products in large quantities with variable size ranges (submicron-to-micron) and improves the applicability of the spray drying technique in food, pharmaceutical, biotechnology, agriculture, and medical industries. 

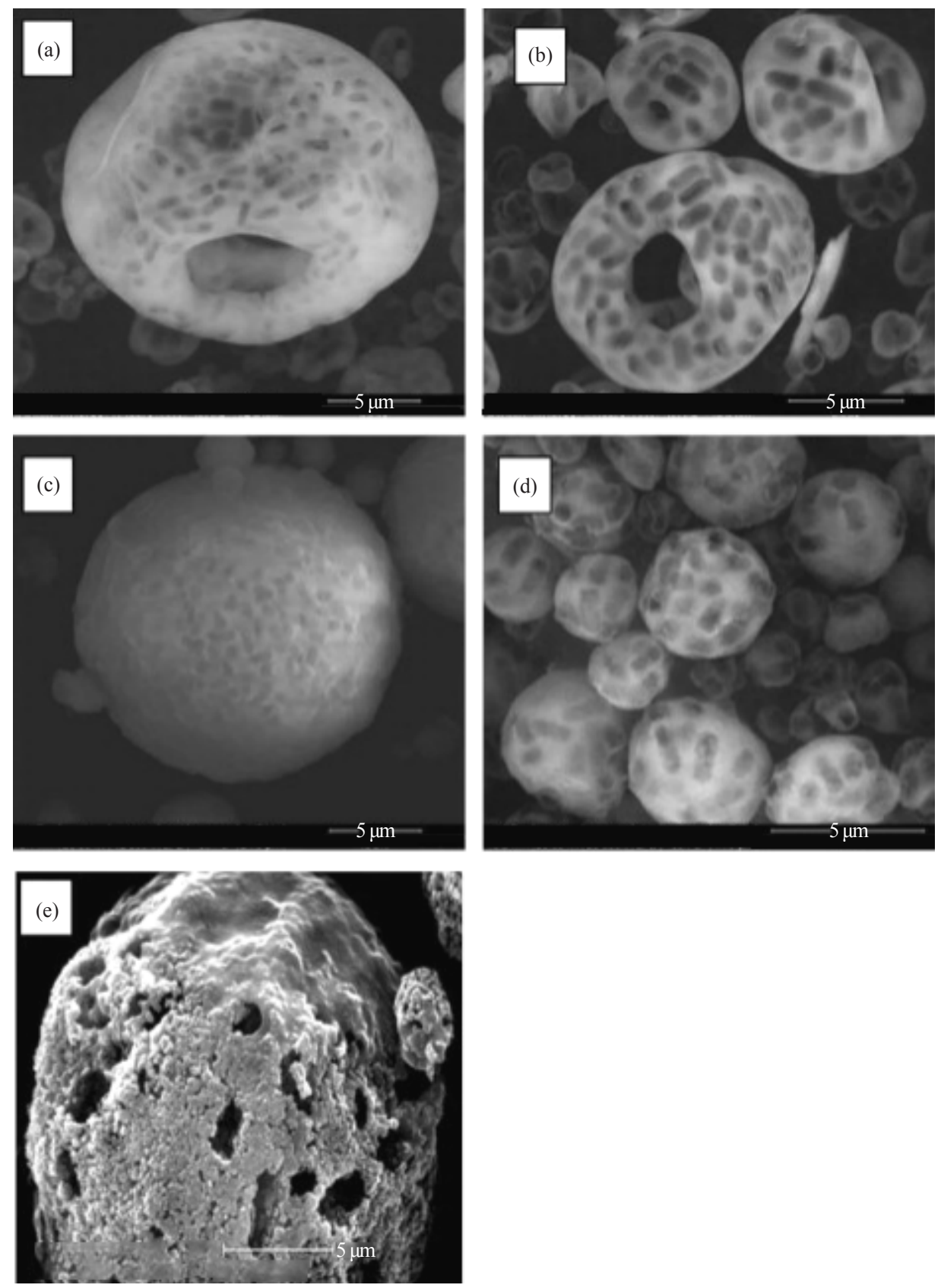

Figure 2. SEM micrographs of microstructures: (a) Spray dried Doughnut Shaped Microstructures (SDSM), (b) incinerated SDSM, (c) Spray dried Spherical Shaped Microstructures (SSSM), (d) incinerated SSSM

and (e) incineratedsilica microstructure. Reprinted with permission from Elsevier [27]

\section{Benefits and limitations of the spray drying process}

The spray drying process offers a number of advantages over other drying methods. Spray drying is a simple, efficient, single-step, reproducible technique, etc. (Figure 3). Spray drying offers cost-effectiveness and scalability which are the important criteria for translation of technology from the lab to market. The added advantage with spray drying is the final product, a dry formulation that helps in reducing the cost of packing and transportation and is therefore preferred in the industry. In comparison to the freeze-drying process, spray drying is a cost-effective and energy-efficient process [40, 41], and therefore, it has been also used as an alternative technique of freeze-drying [42, 43]. 
Using spray drying, it is possible to dry a wide range of components like suspensions, slurry, emulsions, etc. Even, heat-sensitive compounds can also be dried without significant loss in activity. This is possible because although the droplet is exposed to a very high temperature during the drying process however, the exposure time is in the range of milliseconds/seconds. Thus, the activity of the compound is retained. Due to this, pure drug particles and drug/ biomolecule loaded formulations can be prepared using spray drying. It was observed that the spray-dried product has shown an improved life span. It has also gained attention as an immobilizing technique to entrap drugs, microorganisms, aromatic oils, biopolymers, pigments. In one of our studies, spray-dried doxorubicin loaded silica nanoparticles-sodium alginate bio-hybrids carriers have shown better flow property with excellent Polydispersity Index (PDI) value [1].

Although the spray drying process has several benefits, there are a few limitations associated with lab-scale spray dryers. The yield of the spray dryer depends on the work scale which means at large scale spray drying, the yield is high $(\sim 100 \%$ at industry level) however; in the lab, the yield is low (20-70\%) [31-33]. Mostly, loss of product in the walls of the drying chamber is one of the causes of the low yield. Also, due to ineffective separation very fine particles get passed through exhaust air. The preparation of particles at the nanometer size is limited by the low separation capacity of the cyclone and insufficient forces of liquid atomization [30]. This further affects the size and size distribution of the spray-dried products and limits the application of drug delivery systems for intravenous administration [44].

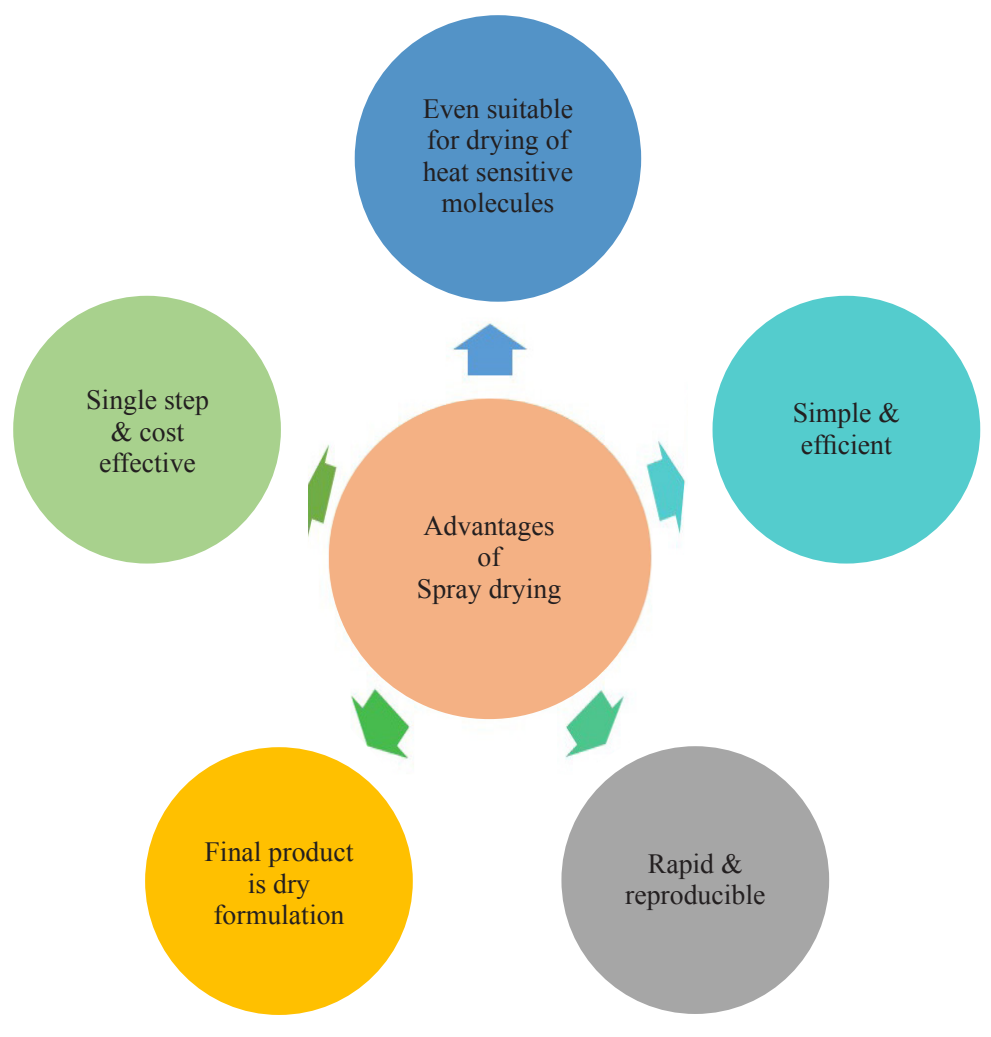

Figure 3. Benefits associated with the spray drying process

\section{Applications of spray drying}

Spray drying is a well-known and widely used technique in the field of the food industry, pharmaceutical, bioprocessing, agriculture, etc. (Figure 4). In 1870, Samuel Percy in the United States patented the spray dryer device for the first time. Afterwards, a number of changes have been incorporated in the spray dryer in order to improve its efficiency and yield. This technique is very promising for application at the laboratory and industrial level as it offers several advantages $[45,46]$.

Herein, the focus is on the applications of spray drying in the food industry, bioprocessing and remediation, and 
drug delivery. These are the areas wherein the spray drying process has been explored and applied in our laboratory.

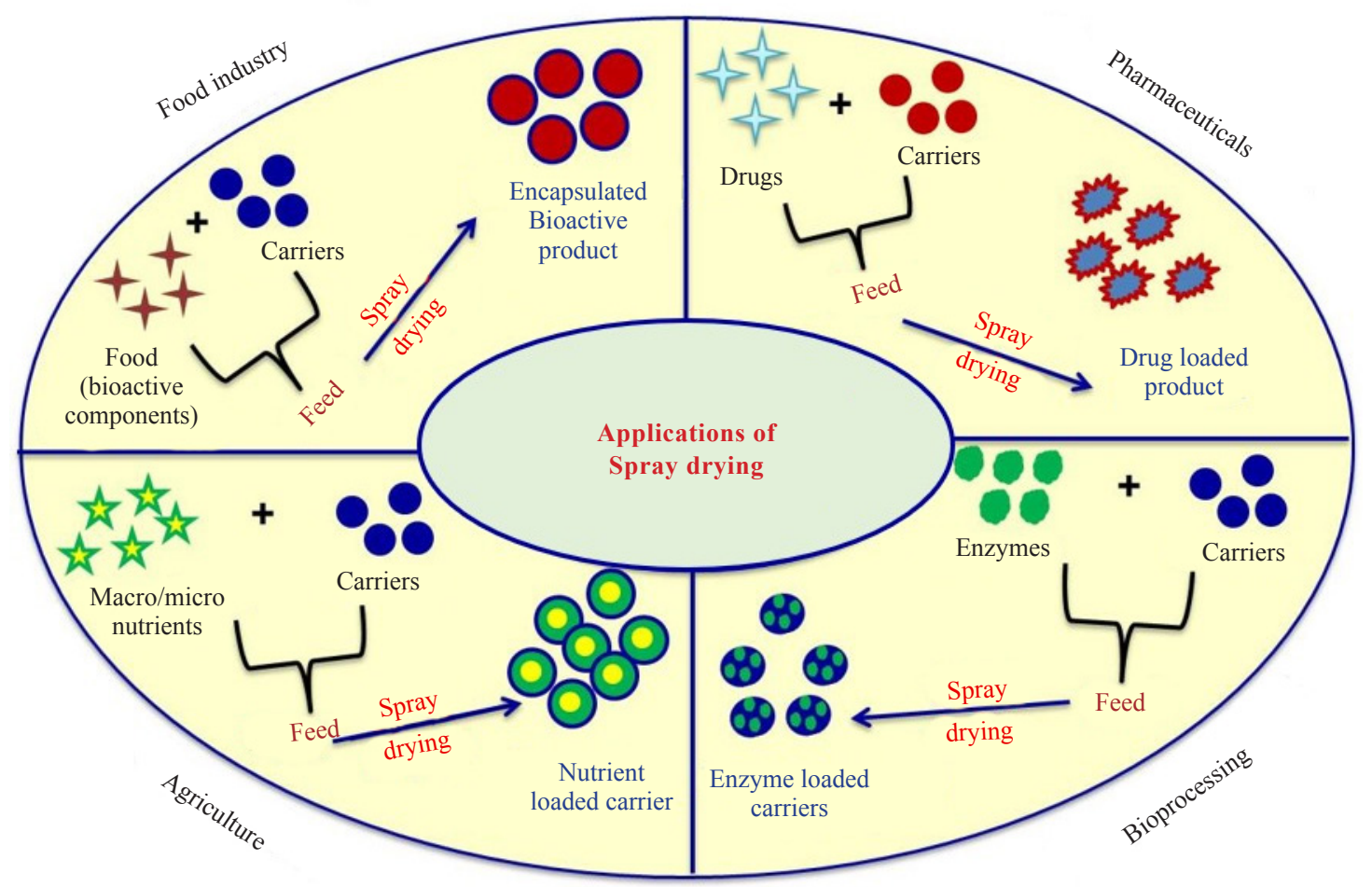

Figure 4. Applications of spray drying technique in various sectors

\subsection{Food industry}

In the food industry, milk was first spray dried into milk powder in the 1920s [47]. Afterwards, the spray drying process has been widely used for synthesizing powdered food products and even juices of various fruits were also spray dried. Quek et al. [48] have sprayed dried watermelon juice with maltodextrin into powder. It was observed that heating at a higher temperature leads to faster water evaporation from feed and the moisture content in the prepared product is less. In previous studies, Ferrari et al. [49] and Kurozawa et al. [50] were performed enzymatic hydrolysis and spray drying to prepare powdered chicken breast protein hydrolysate. Results showed that due to an increase in glass transition temperature (Tg) of the material, the stability of the material was improved. Tonon et al. [51] have used a spray drying process to get powdered products using maltodextrin as the carrier. It was observed that the carrier has helped in reducing the moisture content of the material. Also, the spray drying process was used for drying probiotic cashew apple juice using gum Arabic as a carrier by Pereira et al. [52]. The juices and cells are highly sensitive to heat/drying, still, it was observed that the viability of probiotic cells is maintained in the product, and yield is improved. Different materials like carbohydrates, pectin, starch, gum arabic have been used as the carrier for the preparation of spray-dried products in order to improve the self-life of entrapped ingredients. As reported, sugar beet pectin along with glucose syrup was used for encapsulation of fish oil [53]. Monsoor et al. [54] have reported that the spray drying process did not affect the functional properties of pectin. As per Kenyon et al. [55] maltodextrin showed good oxidative stability to encapsulated oil however, it showed poor emulsion stability, emulsifying capacity, and low oil retention. Yoshii et al. [56] have observed that the encapsulation of emulsified ethyl butyrate was dependent on the concentration of maltodextrin and the type of emulsifier, during the spray drying process.

Gum arabic is a polymer (comprising of D-glucuronic acid, D-galactose, L-rhamnose, L-arabinose with approximately $2 \%$ protein) and because of its excellent emulsification properties, it is widely used [57, 58]. Krishnan et 
al. [59] have reported gum arabic as a better carrier material for encapsulation of cardamom oleoresin than maltodextrins and modified starch. The added advantage was spray dried product showed a free-flowing property. In 2007, Kanakdande et al. [60] have used gum arabicas carrier material for encapsulation of cumin oleoresin using spray drying. Gum arabic is widely used as the carrier because of its ability to produces stable emulsions over a wide $\mathrm{pH}$ range. Gum arabic has been also used for the encapsulation of lipids [55]. Hogan et al. [61] have studied the spray drying of soy oil in sodium caseinate as the carrier. It was observed that during the process of spray drying, the ratio of oil/protein should not be more than one, otherwise the formed emulsion could be destabilized. Sliwinski et al. [62] have studied and reported the effect of spray drying on the physicochemical properties of oil-in-water emulsions with milk proteins as well as denaturation and aggregation of b-lactoglobulin. Gelatin is a water-soluble material that has also been used in spray drying as the carrier [63]. Bruschi et al. [64] have reported that characteristic features of gelatin microparticles could be improved using mannitol. Imagi et al. [65] have suggested that in comparison to glucose, maltodextrin, maltose, pullulan, and mannitol, gelatin has all the properties (high stabilizing activity, high emulsifying activity, and tendency to form a fine dense network on drying) of an efficient carrier material. It was reported by Yoshii et al., that the addition $(1 \%(\mathrm{w} / \mathrm{w}))$ of gelatin could increase the retention of ethyl butyrate [56]. These are a few examples of carriers that have been applied for the encapsulation of food ingredients. Table 1 shows a list of various spray-dried products with various carrier materials in the food industry. Gharsallaoui et al. [40] have compiled a review on spray drying as a technique for encapsulation of food ingredients and focused on the spray drying technique, various carrier materials used for encapsulation during spray drying, and different food ingredient which has been microencapsulated. The method of encapsulation/entrapment of food and fruits extracts using spray drying has wide applicability. It has emerged as an efficient and remarkable method in the preservation of a large number of nutritional components, enzymes, flavours, microorganisms, etc. It imparts a positive impact and overcomes the limitations associated with other drying processes.

Table 1. List of spray-dried food and fruit products in previous studies

\begin{tabular}{cccc}
\hline S. No. & Food items & Carriers & References \\
\hline 1 & Watermelon & Maltodextrin & {$[48]$} \\
2 & Black cherry pulp & Maltodextrin & {$[49]$} \\
3 & Soy extract & Colloidal silicon dioxide, & {$[66]$} \\
4 & maltodextrin and starch & {$[67]$} \\
5 & Maçaí & Maltodextrin & {$[51]$} \\
6 & Soya oil & Sodium caseinate/carbohydrates & {$[61]$} \\
7 & Lycopene & Gelatin/sucrose & {$[68]$} \\
8 & L-Menthol & Gum arabic/modified starch & {$[69]$} \\
9 & Fish oil & Sugar beet pectin/glucose syrup & {$[53]$} \\
10 & Cardamom oleoresin & Gum arabic/modified starch & {$[70]$} \\
\hline
\end{tabular}

\subsection{Remediation of heavy metals and bioprocessing}

In our laboratory, we have synthesized various spray dried microstructures using silica nanoparticles and biomolecules through the process of spray drying [71, 72]. Microstructures of silica NPs and Streptococcus lactis (S. lactis) cells were prepared, applied for removal of uranium from aqueous solution and recovery of adsorbed uranium were also studied $[27,73]$. It was observed that various morphologies can be achieved by varying the physicochemical 
parameters of the spray drying process. Synthesized product was thoroughly characterized using various physicochemical techniques Scanning Electron Microscope (SEM), Fourier-Transform Infrared spectroscopy (FTIR), and Thermal Gravimetric Analyzer (TGA). Synthesized doughnut shaped microstructures have shown more than 85 $\pm 2 \%$ of total uranium uptake in just $10 \mathrm{~min}$ and $92 \%$ uptake in $120 \mathrm{~min}$. However, while recovery, it was observed that the adsorption capacity of microstructures was reduced from $92 \%$ to $67 \%$ [73]. This may be due to the changes in morphology and loss of adsorption sites after acid and ultrasonics treatment. Also, a bio-hybrid of silica NPs and $S$. cerevisiae cells were prepared using spray drying and applied for removal of mercury $\left(\mathrm{Hg}^{2+}\right)$ from the aqueous solution. Synthesized silica-Saccharomyces cerevisiae microstructures showed $98 \%$ mercury sorption in 30 min and maximum sorption was $185.19 \mathrm{mg} / \mathrm{g}$ [29]. It was reported that synthesized microstructures could be used as the efficient sorbent for the removal of mercury from liquid waste effluent. In summary, spray drying has emerged as an efficient process for synthesizing functionalized silica microstructures using microbial cells as the functionalizing agent. A higher length scale of sorbent has further helped in the easy removal of sorbent once the sorption process is over. Characterization results have shown that functional groups present on the microbial cell surface are easily available for binding to uranium ions and recovery of uranium is also possible from the sorbent.

Because S. lactis cells expresses $\beta$-galactosidase activity, thus in the spray dried microstructures (S. lactis cells and silica NPs), enzyme activity was measured [28] and it was observed that the cells immobilized in microstructures have higher biocatalytic activity than the free cells. A threefold increase in enzyme activity of immobilized cells was observed compared to free cells. Also, a shift in optimum $\mathrm{pH}$ of immobilized cells was observed. The results showed a decrease in Michaelis-Menten constant $\left(\mathrm{K}_{\mathrm{m}}\right)$ value which suggests a favourable interaction between enzyme substrate complex formations when cells were immobilized in microstructures. This study supports the application of the spray dryer as an immobilizing technique for immobilization of heat sensitive biomolecule (whole cells) at an optimum inlet temperature with improved catalytic performance.

\subsection{Drug delivery}

Various drying techniques like freeze drying, spray drying, spray freeze drying and aerosol flow reactor have been used for the preparation of drug loaded formulations. Among all, spray drying is widely used to prepare pharmaceutical powders in various size range varying from nano $(\mathrm{nm})$ to the micro $(\mu \mathrm{m})$ metre scale. It has been also used as the particle engineering technique for the production of inhalation particles because in the spray drying process it is possible to play with the properties like flowability, particle size distribution, moisture content, dispersibility, shape, and crystallinity of the prepared formulations [18].

Further, the practical applicability of the spray drying technique is high because using this it is possible to prepare drug loaded spherical particles with high drug loading, low moisture content, and high production yield [74-76]. Spray dried microspheres of alginate were prepared by Szekalska et al. [77], for the entrapment of ranitidine drug. Synthesized microspheres were thoroughly characterized. It was observed that the microspheres have a smooth surface with $70.9 \%$ drug loading efficiency. The entrapped drug in alginate microspheres has been shown to prolong drug release and followed first-order-kinetics. It was suggested that prepared microspheres can be used as the potential carrier and hold application. In 2018, using the process of spray drying, calcium chloride modified alginate microparticles were prepared by Szekalska et al. [78]. The aim behind the work was to increase the release of freely soluble drugs thus metformin hydrochloride was used as the model drug. It was reported that the drug was encapsulated in alginate microparticles. Changes in the concentration of alginate help prolong drug release. Alginate ( $2 \%)$ cross-linked with $0.1 \% \mathrm{CaCl}_{2}$ showed a prolonged drug rate of dissolution of up to $12 \mathrm{~h}$.

Recently, we have prepared a biohybrid comprising silica NPs and sodium alginate biopolymer as a doxorubicin drug carrier using the spray drying process [1]. The synthesized biohybrid was extensively characterised to understand the changes in physicochemical interactions of various components. Doxorubicin loaded biohybrid showed $\sim 93.7 \%$ drug loading efficiency. During in vitro release study, a slow release of doxorubicin was observed and release was higher at lower $\mathrm{pH}$ (pH-5.5) compare to $\mathrm{pH} 7.4$ (physiological $\mathrm{pH}$ ). The biocompatibility studies were also performed and biohybrid did not show cytotoxicity to normal mouse lymphocytes up to $25 \mu \mathrm{g} / \mathrm{mL}$. Viability studies on lung carcinoma A549 cells treated with doxorubicin loaded biohybrid showed more cells killing than the free doxorubicin. This study reveals the applicability of the spray drying technique to synthesize novel drug delivery formulations with improved cell killing ability and for application in cancer therapy. 


\section{Recent developments in spray drying (Nano-spray based spray drying)}

In order to address the limitations associated with conventional spray dryers, the spray dryer with nano-spray nozzles is developed. The nano-spray based spray dryers have further widened their application. There is also improvement in the yield even in lab scale spray dryers and it is possible to spray dry more complex feeds. Buchi (Labotechnik AG, Switzerland) has introduced nano-spray based spray dryers (Nano Spray Dryer B-90). Nano Spray Dryer B-90 is the recent generation of laboratory scale spray-dryers [79]. This device has shown its applicability for the preparation of fine particles with satisfactory yield using small feed sample amounts (milligrams) [80, 81]. These beneficial characteristics are very important and relevant to developing formulations of expensive biomolecules which are going to be used for intravenous administration.

\section{Conclusion and future prospective}

Spray drying is a well-known technique with added advantages like simple, cost-effective, continuous, easily scalable, and reproducible. This technique has been widely used for dehydration, preservation of products, and preparation of various nano-micro formulations using inorganic/organic materials as the carrier. The added advantage with spray drying is the product is a dry formulation which is preferred in industry and reduces the cost of transportation. The spray drying process has been extensively used in the food industry, bioprocessing and remediation, and drug delivery. The spray drying technique with the nano-spray facility has enabled the preparation of a wide range of formulations varying from nano $(\mathrm{nm})$ to micro $(\mu \mathrm{m})$ could be prepared. Although, it has several advantages still continuous efforts are being made to improve the yield of lab scale spray dryers and develop efficient filters for better separation of spray dried product. Also, studying the spray drying of new feed materials that are highly viscous in nature is another milestone that will further diversify the applicability of the spray drying technique to pharmaceutical products and open a way to market. There is no doubt that addressing the yield and separation issue of spray drying, will be an important technology with applicability from lab table to bedside. Recently, the application of spray drying is diversified to synthesize nano-size biohybrids as carriers for nutrients and plant growth promoting microorganisms which will act as nano-bioformulation and help to tackle the problems related to agriculture.

\section{Conflict of interest}

The authors declare no conflict of interest.

\section{References}

[1] Mishra A, Pandey VK, Shankar BS, Melo JS. Spray drying as an efficient route for synthesis of silica nanoparticlessodium alginate biohybrid drug carrier of doxorubicin. Colloids Surface B: Biointerfaces. 2021; 197: 111445. Available from: https://doi.org/10.1016/j.colsurfb.2020.111445.

[2] Ma X, Zhou B, Deng Y, Sheng Y, Wang C, Pan Y, et al. Study on $\mathrm{CaCO}_{3} / \mathrm{PMMA}$ nanocomposite microspheres by soapless emulsion polymerization. Colloids and Surfaces A: Physicochemical and Engineering Aspects. 2008; 312: 190-194. Available from: https://doi:10.1016/j.colsurfa.2007.06.058.

[3] Yang Y, Kong XZ, Kan CY, Sun CZ. Encapsulation of calcium carbonate by styrene polymerization. Polymers for Advanced Technolies. 1999; 10: 54-59. Available from: https://doi.org/10.1002/(SICI)10991581(199901/02)10:1/2<54::AID-PAT766>3.0.CO;2-J.

[4] Tissot I, Novat C, Lefebvre F, Bourgeat-Lami E. Hybrid latex particles coated with silica. Macromolecules. 2001; 34: 5737-5739. Available from: https://doi.org/10.1021/ma010278r.

[5] Livage J, Coradin T, Roux C. Topical review: Encapsulation of biomolecules in silica gels. Journal of Physics: Condensed Matter. 2001; 13: R673-R691.

[6] Wang X, Ahmed NB, Alvarez GS, Tuttolomondo MV, Hélary C, Desimone MF, et al. Sol-gel encapsulation of biomolecules and cells for medicinal applications. Current Topics in Medicinal Chemistry. 2015; 15(3): $223-244$. 
Available from: https://doi.org/10.2174/1568026614666141229112734.

[7] Fennouh S, Guyon S, Jourdat C, Livage J, Roux C. Encapsulation of bacteria in silica gels. Comptes Rendus de l'Académie des Sciences-Series IIC-Chemistry. 1999; 2(11-13): 625. Available from: https://doi.org/10.1016/ S1387-1609(00)88575-8.

[8] Livage J, Roux C, Da Costa JM, Desportes I, Quinson JF. Immunoassays in sol-gel matrices. Journal of Sol-Gel Science and Technology. 1996; 7: 45-51.

[9] Pope EJA, Braun K, Peterson CM. Bioartificial Organs I: Silica gel encapsulated pancreatic islets for the treatment of diabetes mellitus. Journal of Sol-Gel Science and Technology. 1997; 8: 635-639.

[10] Mishra A, Kumar J, Melo JS. An optical microplate biosensor for the detection of methyl parathion pesticide using a bio-hybrid of Sphingomonas sp. cells-silica nanoparticles. Biosensor and. Bioelectronics. 2017; 87: $332-338$. Available from: https://doi.org/10.1016/j.bios.2016.08.048.

[11] Avnir D, Coradin T, Lev O, Livage J. Recent bio-applications of sol-gel materials. Journal of Material. Chemistry. 2006; 16(11): 1013-1030. Available from: https://doi.org/10.1039/B512706H.

[12] Trogl J, Kuncova G, Kuran P. Bioluminescence of Pseudomonas fluorescens HK44 in the course of encapsulation into silica gel. effect of methanol. Folia Microbiology. 2010; 55(6): 569-575. Available from: https://doi. org/10.1007/s12223-010-0091-9.

[13] Liao YT, Liu CH, Yu J, Wu KC. Liver cancer cells: targeting and prolonged-release drug carriers consisting of mesoporous silica nanoparticles and alginate microspheres. International Journal of Nanomedicine. 2014; 9: 27672778. Available from: https://doi.org/10.2147/IJN.S60171.

[14] Mishra A, Melo JS, Agrawal A, Kashyap Y, Sen D. Preparation and application of silica nanoparticles-Ocimum basilicum seeds bio-hybrid for the efficient immobilization of invertase enzyme. Colloids Surface B. Biointerfaces. 2020; 188: 110796. Available from: https://doi.org/10.1016/j.colsurfb.2020.110796.

[15] Mishra A, Kumar J, Melo JS. Silica based bio-hybrid materials and their relevance to bionanotechnology. Austin Journal of Plant Biology. 2020; 6(1): 1024-1028. Available from: https://doi.org/ajpb-v6-id1024.

[16] Vallet-Regí M, Colilla M, Izquierdo-Barba I, Manzano M. Mesoporous silica nanoparticles for drug delivery: current insights. Molecules. 2017; 23(47): 1-19. Available from: https://doi.org/10.3390/molecules23010047.

[17] Jiang S, Hua L, Guo Z, Sun L. One-pot green synthesis of doxorubicin loaded-silica nanoparticles for in vivo cancer therapy. Material Science Engineering C Materials for Biological Applications. 2018; 90: $257-263$. Available from: https://doi.org/10.1016/j.msec.2018.04.047.

[18] Malamatari M, Charisi A, Malamataris S, Kachrimanis K, Nikolakakis I. Spray Drying for the preparation of nanoparticle-based drug formulations as dry powders for inhalation. Processes. 2020; 8(7): 788. Available from: https://doi.org/10.3390/pr8070788.

[19] Bhatia R, Brinker C, Gupta A, Singh A. Aqueous sol-gel process for protein encapsulation. Chemistry of Materials. 2000; 12: 2434-2441.

[20] Depagne C, Roux C, Coradin T. How to design cell-based biosensors using the sol-gel process. Analytical and Bioanalytical Chemistry. 2011; 400(4): 965-976. Available from: https://oi.org/10.1007/s00216-010-4351-y.

[21] Ye H, Guo Z, Peng M, Cai C, Chen Y, Cao Y, et al. Methyl parathion degrading enzyme-based nano-hybrid biosensor for enhanced methyl parathion recognition. Electroanalytical. 2016; 28: 1591-1596. Available from: https://doi.org/10.1002/elan.201501102.

[22] Ponamoreva ON, Kamanina OA, Alferov VA, Machulin AV, Rogova TV, Arlyapov VA, et al. Yeast-based selforganized hybrid bio-silica sol-gels for the design of biosensors. Biosensor and Bioelectronics. 2015; 67: $321-326$. Available from: https://doi.org/10.1016/j.bios.2014.08.045.

[23] Hamm CE, Merkel R, Springer O, Jurkojc P, Maier C, Prechtel K, et al. Architecture and material properties of diatom shells provide effective mechanical protection. Nature. 2003; 421: 841-843. Available from: https://doi. org/10.1038/nature01416.

[24] Nassif N, Bouvet O, NoelleRager M, Roux C, Coradin T, Livage J. Living bacteria in silica gels. Nature Materials. 2002; 1: 42-44. Available from: https://doi.org/10.1038/nmat709.

[25] Blondeau M, Coradin T. Living materials from sol-gel chemistry: current challenges and perspectives. Journal of Materials Chemistry. 2012; 22(42): 22335-22343. Available from: https://doi.org/10.1039/C2JM33647B.

[26] Melo JS, Tripathi A, Kumar J, Mishra A, Bhanu S, Bhainsa K. Immobilization: then and now. In: Tripathi A, Melo JS. (Eds.) I Immobilization Strategies. Gels Horizons: From Science to Smart Materials. Singapore: Springer; 2020. p. 1-84.

[27] Mishra A, Melo JS, Sen D, D’Souza SF. Evaporation induced self assembled microstructures of silica nanoparticles and Streptococcus lactis cells as sorbent for uranium (VI). Journal of Colloid and Interface Science. 2014; 414: 33- 
40. Available from: http://dx.doi.org/10.1016/j.jcis.2013.09.046.

[28] Mukundan S, Melo JS, Sen D, Bahadur J. Enhancement in $\beta$-galactosidase activity of Streptococcus lactis cells by entrapping in microcapsules comprising of correlated silica nanoparticles. Colloids Surface B: Biointerfaces. 2020; 195: 111245. Available from: https://doi.org/10.1016/j.colsurfb.2020.111245.

[29] Shukla P, Mishra A, Manivannan S, Melo JS, Mandal D. Parametric optimization for adsorption of mercury (II) using self-assembled bio-hybrid. Journal of Environmental Chemical Engineering. 2020; 8(3): 103725. Available from: https://doi.org/10.1016/j.jece.2020.103725.

[30] Sosnik A, Seremeta KP. Advantages and challenges of the spray-drying technology for the production of pure drug particles and drug-loaded polymeric carriers. Advances in Colloid and Interface Science. 2015; 223: 40-54. Available from: https://doi.org/10.1016/j.cis.2015.05.003.

[31] Rabbani NR, Seville PC. The influence of formulation components on the aerosolisation properties of spraydried powders. Journal of Control Release. 2010; 110: 130-140. Available from: https://doi.org/10.1016/ j.jconrel.2005.09.004.

[32] Li X, Anton N, Arpagaus C, Belleteix F, Vandamme TF. Nanoparticles by spray drying using innovative new technology: the Büchi nano spray dryer B-90. Journal of Control Release. 2010; 147: 304-310. Available from: https://doi.org/10.1016/j.jconrel.2010.07.113.

[33] Lee SH, Heng D, Ng WK, Chan HK, Tan RB. Nano spray drying: a novel method for preparing protein nanoparticles for protein therapy. International Journal of Pharmaceutics. 2011; 403(1-2): 192-200. Available from: https://doi.org/10.1016/j.ijpharm.2010.10.012.

[34] Elversson J, Millqvist-Fureby A, Alderborn G, Elofsson U. Droplet and particle size relationship and shell thickness of inhalable lactose particles during spray drying. Journal of Pharmaceutical Sciences. 2003; 92: 900910. Available from: https://doi.org/10.1002/jps.10352.

[35] Fatnassi M, Tourné-Péteilh C, Peralta P, Cacciaguerra T, Dieudonné P, Devoisselle JM. Encapsulation of complementary model drugs in spray-dried nanostructured materials. Journal of Sol-Gel Science Technology. 2013; 68: 307-316. Available from: https://doi.org/10.1007/s10971-013-3170-y.

[36] Schoubben A, Blasi P, Giovagnoli S, Rossi C, Ricci M. Development of a scalable procedure for fine calcium alginate particle preparation. Chemical Engineering Journal. 2010; 160: 363-369. Available from: https://doi. org/10.1016/j.cej.2010.02.062.

[37] Berggren J, Frenning G, Alderborn G. Compression behaviour and tablet-forming ability of spray-dried amorphous composite particles. European Journal of Pharmaceutical Sciences. 2004; 22(2-3): 191-200. Available from: https://doi.org/10.1016/j.ejps.2004.03.008.

[38] Mu L, Teo MM, Ning HZ, Tan CS, Feng SS. Novel powder formulations for controlled delivery of poorly soluble anticancer drug: application and investigation of TPGS and PEG in spray-dried particulate system. Journal of Control Release. 2005; 103(3): 565-575. Available from: https://doi.org/10.1016/j.jconrel.2004.12.023.

[39] Alamilla-Beltran L, Chanona-Perez JJ, Jimenez-Aparicio AR, GuiterrezLopez GF. Description of morphological changes of particles along spray drying. Journal of Food Engineering. 2005; 67: 179-184. https://doi.org/10.1016/ j.jfoodeng.2004.05.063.

[40] Gharsallaoui A, Roudaut G, Chambin O, Voilley A, Saurel R. Applications of spray drying in microencapsulation of food ingredients: an overview. Food Research International. 2007; 40: 1107-1121. Available from: https://doi. org/10.1016/j.foodres.2007.07.004.

[41] Mahdavi SA, Jafari SM, Ghorbani M, Assadpoor E. Spray-drying microencapsulation of anthocyanins by natural biopolymers: a review. Drying Technology. 2014; 32: 509-518. Available from: https://doi.org/10.1080/07373937.2 013.839562.

[42] Lane ME, Brennan FS, Corrigan OI. Comparison of post-emulsification freeze drying or spray drying processes for the microencapsulation of plasmid DNA. Journal of Pharmacy and Pharmacology. 2005; 57(7): 831-838. Available from: https://doi.org/10.1211/0022357056406.

[43] Takashima Y, Saito R, Nakajima A, Oda M, Kimura A, Kanazawa T. Spray drying preparation of microparticles containing cationic PLGA nanospheres as gene carriers for avoiding aggregation of nanospheres. International Journal of Pharmaceutics. 2007; 343(1-2): 262-269. Available from: https://doi.org/10.1016/j.ijpharm.2007.05.042.

[44] Andrade F, Rafael D, Videira M, Ferreira D, Sosnik A, Sarmento B. Nanotechnology and pulmonary delivery to overcome resistance in infectious diseases. Advanced Drug Delivery Reviews. 2013; 65(13-14): 1816-1827. Available from: https://doi.org/10.1016/j.addr.2013.07.020.

[45] Wan F, Bohr A, Maltesen MJ, Bjerregaard S, Foged C, Rantanen J. Critical solvent properties affecting the particle formation process and characteristics of celecoxib-loaded PLGA microparticles via spray-drying. Pharmaceutical 
Research. 2013; 30(4): 1065-1076. Available from: https://doi.org/10.1007/s11095-012-0943-x.

[46] Krishnaiah D, Sarbatly R, Nithyanandam R. Microencapsulation of Morinda citrifolia L. extract by spray-drying. Chemical Engineering Research and Design. 2012; 90(5): 622-632. Available from: https://doi.org/10.1016/ j.cherd.2011.09.003.

[47] Costa SS, Machado BAS, Martin AR, Bagnara F, Ragadalli SAA, Alves ARC. Drying by spray drying in the food industry: Micro-encapsulation, process parameters and main carriers used. African Journal of Food Science. 2015; 9(9): 462-470. Available from: https://doi.org/10.5897/AJFS2015.1279.

[48] Quek SY, Chok NK, Swedlund P. The physicochemical properties of spray-dried watermelon powders. Chemical Engineering and Processing: Process Intensification. 2007; 46(5): 386-392. Available from: https://doi. org/10.1016/j.cep.2006.06.020.

[49] Ferrari CC, Ribeiro CP, Aguirre JM. Spray drying of blackberry pulp using maltodextrin as carrier agent. Brazilian Journal of Food Technology. 2012; 15(2): 157-165. Available from: https://doi.org/10.1590/S198167232012005000009 .

[50] Kurozawa LE, Park KJ, Hubinger MD. Spray Drying of chicken meat protein hydrolysate: Influence of process conditions on powder property and dryer performance. Drying Technology. 2011; 29(2): 163-173. Available from: https://doi.org/10.1080/07373937.2010.482711.

[51] Tonon RV, Brabet C, Hubinger MD. Influence of process conditions on the physicochemical properties of acai (Euterpe oleraceae Mart.) powder produced by spray drying. Journal of Food Engineering. 2008; 88(3): 411-418. Available from: https://doi.org/10.1016/j.jfoodeng.2008.02.029.

[52] Pereira ALF, Almeida FDL, Lima MA, Costa JMC, Rodrigues S. Spray-drying of probiotic cashew apple juice. Food Bioprocess Technology. 2014; 7: 2492-2499. Available from: https://doi.org/10.1007/s11947-013-1236-z.

[53] Drusch S. Sugar beet pectin: A novel emulsifying wall component for microencapsulation of lipophilic food ingredients by spray-drying. Food Hydrocolloids. 2007; 21(7): 1223-1228. Available from: https://doi.org/10.1016/ j.foodhyd.2006.08.007.

[54] Monsoor MA. Effect of drying methods on the functional properties of soy hull pectin. Carbohydrate Polymers. 2005; 61: 362-367. Available from: https://doi.org/10.1016/J.CARBPOL.2005.06.009.

[55] Kenyon MM. Modified starch, maltodextrin, and corn syrup solids as wall materials for food encapsulation. In Risch SJ, Reineccius GA. (Eds.) Encapsulation and Controlled Release of Food Ingredients. ACS symposium series.Washington, DC: American Chemical Society; 1995. p. 42.

[56] Yoshii H, Soottitantawat A, Liu X-D, Atarashi T, Furuta T, Aishima S. Flavor release from spray-dried maltodextrin/gum arabic or soy matrices as a function of storage relative humidity. Innovative Food Science and Emerging Technologies. 2001; 2: 55-61. Available from: https://doi.org/10.1016/S1466-8564(01)00019-4.

[57] Radford SJ, Dickinson E, Golding M. Stability and rheology of emulsions containing sodium caseinate: Combined effects of ionic calcium and non-ionic surfactant. Journal of Colloid and Interface Science. 2004; 274(2): 673-686. Available from: https://doi.org/10.1016/j.jcis.2003.12.045.

[58] Dickinson E. Hydrocolloids at interfaces and the influence on the properties of dispersed systems. Food Hydrocolloids. 2003; 17(1): 25-39. Available from: https://doi.org/10.1016/S0268-005X(01)00120-5.

[59] Krishnan S, Bhosale R, Singhal RS. Microencapsulation of cardamom oleoresin: Evaluation of blends of gum arabic, maltodextrin and a modified starch as wall materials. Carbohydrate Polymers. 2005; 61(1): 95-102. Available from: https://doi.org/10.1016/j.carbpol.2005.02.020.

[60] Kanakdande D, Bhosale R, Singhal RS. Stability of cumin oleoresin microencapsulated in different combination of gum arabic, maltodextrin and modified starch. Carbohydrate Polymers. 2007; 67(4): 536-541. Available from: https://doi.org/10.1016/j.carbpol.2006.06.023.

[61] Hogan SA, McNamee NF, O'Riordan ED, O'Sullivan M. Emulsification and microencapsulation properties of sodium caseinate/carbohydrate blends. International Dairy Journal. 2001; 11(3): 137-144. Available from: https:// doi.org/10.1016/S0958-6946(01)00091-7.

[62] Sliwinski EL, Lavrijsen BWM, Vollenbroek JM, Stege HJVD, Boekel MAJSV, Wouters JTM. Effects of spray drying on physicochemical properties of milk protein stabilised emulsions. Colloids and Surfaces B: Biointerfaces. 2003; 31(1): 219-229. Available from: https://doi.org/10.1016/S0927-7765(03)00142-5.

[63] Lee SW, Kim MH, Kim CK. Encapsulation of ethanol by spray drying technique: Effects of sodium lauryl sulfate. International Journal of Pharmaceutics. 1999; 187(2): 193-198. Available from: https://doi.org/10.1016/S03785173(99)00185-4.

[64] Bruschi ML, Cardoso MLC, Lucchesi MB, Gremiao MPD. Gelatin microparticles containing propolis obtained by spraydrying technique: Preparation and characterization. International Journal of Pharmaceutics. 2003; 264(1-2): 
45-55. Available from: https://doi.org/10.1016/S0378-5173(03)00386-7.

[65] Imagi J, Yamanouchi T, Okada K, Tanimoto M, Matsuno R. Properties of agents that effectively entrap liquid lipids. Bioscience Biotechnology and Biochemistry. 1992; 56(3): 477-480. Available from: https://doi.org/10.1271/ bbb.56.477.

[66] Georgetti SR, Casagrande R, Souza CRF, Oliveira WP, Fonseca MJV. Spray drying of the soybean extract: effects on chemical properties and antioxidant activity. LWT-Food Science and Technology. 2008; 41(8): 1521-1527. Available from: https://doi.org/10.1016/j.lwt.2007.09.001.

[67] Abadio FDB, Domingues AM, Borges SV, Oliveira VM. Physical properties of powdered pineapple (Ananas comosus) juice-effect of malt dextrin concentration and spray drying speed. Journal of Food Engineering. 2004; 64(3): 285-287. Available from: https://doi.org/10.1016/j.jfoodeng.2003.10.010.

[68] Shu B, Yu W, Zhao Y, Liu X. Study on microencapsulation of lycopene by spray-drying. Journal of Food Engineering. 2006; 76(4): 664-669. Available from: https://doi.org/10.1016/j.jfoodeng.2005.05.062.

[69] Soottitantawat A, Takayama K, Okamura K, Muranaka D, Yoshii H, Furuta T. Microencapsulation of L-menthol by spray drying and its release characteristics. Innovative Food Science and Emerging Technologies. 2005; 6(2): 163170. Available from: https://doi.org/10.1016/j.ifset.2004.11.007.

[70] Shaikh J, Bhosale R, Singhal R. Microencapsulation of black pepper oleoresin. Food Chemistry. 2006; 94(1): 105110. Available from: https://doi.org/10.1016/j.foodchem.2004.10.056.

[71] Sen D, Melo JS, Bahadur J, Mazumder S, Bhattacharya S, D’Souza SF, et al. Arrest of morphological transformation during evaporation-induced self-assembly of mixed colloids in micrometric droplets by charge tuning. Soft Matter. 2011; 7: 5423-5429. Available from: https://doi.org/10.1039/C1SM05100H.

[72] Melo JS, Sen D, Mazumder S, D’Souza SF. Spray drying as a novel technique for obtaining microbial imprinted microspheres and its application in filtration. Soft Matter. 2013; 9(3): 805-810. Available from: https://doi. org/10.1039/C2SM26825F.

[73] Lahiri S, Mishra A, Mandal D, Bhardwaj RL, Gogate PR. Sonochemical recovery of uranium from nanosilicabased sorbent and its biohybrid. Ultrasonics Sonochemistry. 2021; 76: 105667. Available from: https://doi. org/10.1016/j.ultsonch.2021.105667.

[74] Patel BB, Patel JK, Chakraborty S. Review of patents and application of spray drying in pharmaceutical, food and flavor industry. Recent Patents on Drug Delivery \& Formulation. 2014; 8(1): 63-78. Available from: https://doi.org $/ 10.2174 / 1872211308666140211122012$.

[75] Bagheri L, Madadlou A, Yarmand M, Mousavi ME. Spray-dried alginate microparticles carrying caffeine-loaded and potentially bioactive nanoparticles. Food Research International. 2014; 62: 1113-1119. Available from: https:// doi.org/10.1016/j.foodres.2014.05.040.

[76] Santa-Maria M, Scher H, Jeoh T. Microencapsulation of bioactives in cross-linked alginate matrices by spray drying. Journal of Microencapsulation. 2012; 29(3): 286-295. Available from: https://doi.org/10.3109/02652048.2 011.651494.

[77] Szekalska M, Amelian A, Winnicka K. Alginate microspheres obtained by the spray drying technique as mucoadhesive carriers of ranitidine. Acta Pharmaceutica. 2015; 65(1): 15-27. Available from: https://doi. org/10.1515/acph-2015-0008.

[78] Szekalska M, Sosnowska K, Czajkowska-Kosnik A, Winnicka K. Calcium chloride modified alginate microparticles formulated by the spray drying process: a strategy to prolong the release of freely soluble drugs. Materials. 2018; 11(9): 1522. Available from: https://doi.org/10.3390/ma11091522.

[79] Heng D, Lee SH, Ng WK, Tan RB. The nano spray dryer B-90. Expert Opinion on Drug Delivery. 2011; 8(7): 965972. Available from: https://doi.org/10.1517/17425247.2011.588206.

[80] Schmid K, Arpagaus C, Friess W. Evaluation of the Nano Spray Dryer B-90 for pharmaceutical applications. Pharmaceutical Development and Technology. 2011; 16(4): 287-294. Available from: https://doi.org/10.3109/1083 7450.2010 .485320 .

[81] Lee SH, Teo J, Heng D, Ng WK, Chan HK, Tan RB. Synergistic combination dry powders for inhaled antimicrobial therapy: formulation, characterization and in vitro evaluation. European journal of Pharmaceutics and Biopharmaceutics. 2013; 83(2): 275-284. Available from: https://doi.org/10.1016/j.ejpb.2012.09.002. 